\title{
Role of ferric carboxymaltose in the treatment of postpartum anemia in a tertiary care hospital in Andhra Pradesh
}

\author{
Kirtan Krishna $^{1 *}$, Achint Krishna ${ }^{2}$, Divya Teja G. N. ${ }^{3}$
}

\author{
${ }^{1}$ Department of Obstetrics and Gynecology, ${ }^{2}$ Department of Medicine, P.E.S. Institute of Medical Sciences and Research, \\ Kuppam, Andhra Pradesh, India \\ ${ }^{3}$ Consultant, Vinayaka Hospital, Bhimavarm, Andhra Pradesh, India
}

Received: 01 August 2021

Accepted: 02 September 2021

*Correspondence:

Dr. Kirtan Krishna,

E-mail: kirtank1@gmail.com

Copyright: () the author(s), publisher and licensee Medip Academy. This is an open-access article distributed under the terms of the Creative Commons Attribution Non-Commercial License, which permits unrestricted non-commercial use, distribution, and reproduction in any medium, provided the original work is properly cited.

\begin{abstract}
Background: Postpartum iron deficiency anemia is common in India as a consequence of postpartum hemorrhage. Recent studies have evaluated the use of parenteral iron as a better tolerated treatment modality. Compared with oral iron supplements, parenteral iron is associated with a rapid rise in serum ferritin and hemoglobin and improved maternal fatigue scores in the postpartum period. Parenteral iron may be considered for the treatment of postpartum anemia. The objective of the study was to evaluate the efficacy, safety, and tolerability of intravenous ferric carboxymaltose, in women with postpartum anemia.

Methods: A clinical observational study was undertaken in a tertiary care hospital, 50 women within six weeks of delivery with $\mathrm{Hb} \geq 6 \mathrm{gm} / \mathrm{dl}$ and $\leq 10 \mathrm{gm} / \mathrm{dl}$ received $1000 \mathrm{mg} / \mathrm{week}$, over 15 minutes or less, repeated weekly to a calculated replacement dose (maximum $2500 \mathrm{mg}$ ). Hemoglobin and serum ferritin levels were recorded prior to treatment and on day 21 after completion of treatment.

Results: Ferric carboxymaltose-treated subjects achieved a hemoglobin greater than $12 \mathrm{gm} / \mathrm{dL}$ in a short time period (21 days), achieve a hemoglobin rise of $\geq 3 \mathrm{gm} / \mathrm{dL}$ more quickly, and attain higher serum ferritin levels. It is also associated with better patient compliance, and shorter treatment period. Drug-related adverse events occurred less frequently with ferric carboxymaltose. The only noted disadvantage was that it is more expensive when compared to other iron preperations.

Conclusions: Intravenous ferric carboxymaltose was safe and well tolerated with good efficacy and better patient compliance in the treatment of postpartum iron deficiency anemia.
\end{abstract}

Keywords: Ferric carboxymaltose, Hemoglobin, Parenteral iron, Postpartum anemia, Serum ferritin

\section{INTRODUCTION}

In modern times, the health of mother has greatly improved due to advances in knowledge and technology. However in developing countries like India there has been limited progress in reducing the maternal mortality. Most maternal deaths in the past decade has occurred as a consequence of the poor health and nutritional status of the mother coupled with inadequate care before, during, and after delivery. Unfortunately the problem continues as it is accepted as inevitable in many societies, because it is so common. It is widely thought that improvements in newborn and maternal health require sophisticated and expensive technologies and highly specialized staff. However what is actually needed is essential care during pregnancy, the assistance of a person with midwifery skills during childbirth and the immediate postpartum period, and a few critical interventions for the newborn and mother.

Iron deficiency anemia, defined by the World Health Organization as a hemoglobin $(\mathrm{Hb})$ less than $12 \mathrm{gm} / \mathrm{dl}$, is 
the most common cause of anemia in the postpartum period, with rates as high as $37 \%$ reported in the first postpartum week. ${ }^{1,2}$ The prevalence of postpartum anemia varies from $4 \%$ to $27 \% .^{3}$ In a survey from a north Indian village, about $70 \%$ women in the postpartum period were found to be anemic. ${ }^{4}$ Postpartum anemia is caused primarily by inadequate iron intake prior to and during pregnancy and by peripartum blood loss. ${ }^{5,6}$ Each $\mathrm{ml}$ of blood loss results in loss of $0.5 \mathrm{mg}$ iron. About $20 \%$ of maternal deaths worldwide can be attributed to anemia. ${ }^{7}$ In India, about $36 \%$ of the total maternal deaths are attributable to postpartum hemorrhage or anemia. ${ }^{8}$ In healthy women after normal delivery, the prevalence of anemia one week postpartum is $14 \%$ in iron-supplemented women and $24 \%$ in nonsupplemented women. ${ }^{9}$

Patients with postpartum anemia have a longer average length of hospital stay, are more likely to receive a blood transfusion, and incur higher hospitalization costs. ${ }^{10}$ Postpartum anemia has been associated with postpartum depression, stress, anxiety, cognitive impairment, poor mother-infant interactions, and delayed infant development. ${ }^{2,11,12}$ Infants of mothers with iron deficiency anemia have lower developmental test scores at 10 weeks, and these developmental deficits in infants of iron deficient mothers have been shown to persist at nine months of age, even after correction of maternal iron status. ${ }^{12}$

Currently, the Center for Disease Control and Prevention (CDC; Atlanta, Georgia) recommends selective anemia screening at four to six weeks postpartum for women who have had "anemia continued through the third trimester," "excessive blood loss during delivery" and "multiple births". ${ }^{13}$ For a diagnosis of iron deficiency anemia, it must also be shown that the patient is iron deficient. Serum ferritin has been regarded as the gold standard in establishing iron deficiency, with the most useful laboratory measure of iron status which generally accepted cut-off level for serum ferritin, below which iron stores are considered to be depleted is, $<15 \mathrm{ng} / \mathrm{ml}$ and ferritin level $<12 \mathrm{ng} / \mathrm{ml}$ is associated with iron deficiency anemia. ${ }^{14,15}$

Despite a paucity of definite evidence for substantial benefit to either mother or child, the overwhelming consensus appears to be that iron deficiency anemia in the postpartum period should be treated quite vigorously. The standard approach to treatment in the majority of UK institutions is oral iron supplementation, with blood transfusion reserved for more severe or symptomatic cases. However, the transfusion trigger is clinician dependant and a number of studies and audits have shown that the transfusion level varies widely between medical teams and institutions, with a significant proportion of transfusions given inappropriately. ${ }^{16}$

Oral iron supplementation is more commonly used than blood transfusion for postpartum IDA. However, it is unreliable in the treatment of severe anaemia due to its limited absorption and gastrointestinal adverse effects that affect compliance. ${ }^{17,18}$

Iron sucrose is typically administered as a slow push injection or a 15- to 30-minute infusion in doses of 100$200 \mathrm{mg}$, requiring multiple outpatient visits and repeated intravenous access for patients to receive the standard therapeutic course of $1,000 \mathrm{mg}$ elemental iron. Iron dextran can be administered as a single dose, but this requires administration over a period of four to six hours. In addition, iron dextran complexes can cause fatal dextran-induced anaphylactic reactions. ${ }^{19,20}$ Anaphylactic reaction is rare, with estimates for iron dextran products of $0.6 \%$ incidence. $^{21}$

Ferric carboxymaltose is a novel non-dextran-containing complex of iron that allows for administration of a large replenishment dose $(\leq 1,000 \mathrm{mg}$ of iron) over a short infusion period (15-30 minutes), typically to the amount required for iron repletion. Ferric carboxymaltose is effective in improving hemoglobin concentration in nondialysis-dependent patients with $\mathrm{CKD} .{ }^{22}$ It may be of significant benefit for use in the outpatient department or in a community setting as a result of its rapid and highdose replacement of depleted iron stores in patients with $\mathrm{CKD}$, as well as in various other adult populations with iron deficiency anaemia. ${ }^{22}$

Our study was designed to test the hypothesis that ferric carboxymaltose is an effective drug for correction of postpartum iron deficiency anemia.

\section{METHODS}

This study was conducted in a tertiary care hospital (PESIMSR) in a rural setting between $1^{\text {st }}$ November 2014 and $31^{\text {st }}$ August 2015. An institutional review board approved the study protocol for the study prior to initiation. All subjects gave written informed consent before enrolment. Healthy women 6 weeks or less after delivery with postpartum anemia (local laboratory $\mathrm{Hb} \geq 6$ $\mathrm{gm} / \mathrm{dl}$ and $\leq 10 \mathrm{gm} / \mathrm{dl}$ and serum ferritin less than $15 \mu \mathrm{g} / \mathrm{l}$ ) requiring iron supplementation and willing to participate in the study were enrolled (Figure 1).

Demographic and standard laboratory data was collected on admission. Once patients were enrolled, detailed history and clinical examination was done.

Exclusion criteria included significant vaginal bleeding (estimated blood loss greater than $1000 \mathrm{cc}$ ) in the 24 hours prior to enrolment, a history of anemia other than iron deficiency anemia or blood loss due to delivery, current treatment with myelosuppressive therapy or asthma therapy, recent blood transfusions, or erythropoietin within three months prior to screening, bleeding disorders and hemoglobinopathies.

Study withdrawal was required if the subject required an intervention (i.e., erythropoietin, blood transfusion, 
intravenous or oral iron outside the study protocol). Subjects whose study medication was discontinued for safety reasons remained in the study. Subjects were counselled about the advantages and adverse effects of ferric carboxymaltose and advised to take the study medication. The dosage of ferric carboxymaltose was based on patient's body weight and $\mathrm{Hb}$ level (Table 1).

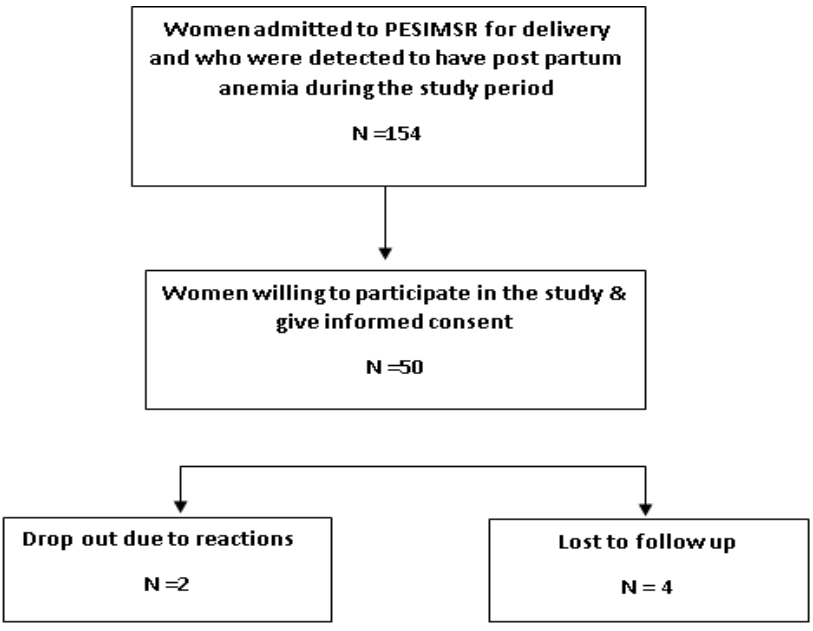

Figure 1: Study design.

Table 1: Dosage of ferric carboxymaltose based on patient's body weight.

\begin{tabular}{|lll|}
\hline Hb $($ gm/dl) & $\begin{array}{l}\text { Patient body } \\
\text { weight } \geq 35 \mathrm{~kg} \\
\text { and }<70 \mathrm{~kg}\end{array}$ & $\begin{array}{l}\text { Patient body } \\
\text { weight } \geq 70 \mathrm{~kg}\end{array}$ \\
\hline less than $\mathbf{1 0}$ gm/dl & $1500 \mathrm{mg}$ & $2000 \mathrm{mg}$ \\
\hline$\geq \mathbf{1 0}$ gm/dl & $1000 \mathrm{mg}$ & $1500 \mathrm{mg}$ \\
\hline
\end{tabular}

Ferric carboxymaltose was given weekly until the individual's calculated cumulative dose had been reached or a maximum of $2000 \mathrm{mg}$ of ferric carboxymaltose had been administered. The maximum single weekly dose of ferric carboxymaltose was not to exceed $1000 \mathrm{mg} / \mathrm{dose}$, administered intravenously over 15 minutes or less. The dilution of FCM injection for i.v. drip was done based on the prescribed format (Table 2).

Table 2: Dilution plan of FCM injection for i.v. drip infusion.

\begin{tabular}{|lll|}
\hline FCM & Iron & $\begin{array}{l}\text { Max amount of sterile } \\
\mathbf{0 . 9 \%} \mathbf{~ N a C l} \text { solution }\end{array}$ \\
\hline $\mathbf{2}$ to $4 \mathrm{ml}$ & $100-200 \mathrm{mg}$ & $50 \mathrm{ml}$ \\
\hline $\mathbf{4}$ to10 $\mathbf{~ m l}$ & $200-500 \mathrm{mg}$ & $100 \mathrm{ml}$ \\
\hline
\end{tabular}

Each $\mathrm{ml}$ contains $50 \mathrm{mg}$.

Central laboratory assessment of $\mathrm{Hb} \%$ and serum ferritin were performed on days 0 and 21 days after the last dose of parenteral iron. This observational study was designed to evaluate the efficacy, safety, and tolerability of ferric carboxymaltose compared with oral iron in women with postpartum anemia.
The procedure was explained to the subjects in their own colloquial language. Side effects such as headache, myalgia, arthralgia, nausea, vomiting, epigastric discomfort and anaphylactoid reactions were looked for during the procedure. The patients were observed for one hour after infusion after which they were allowed to go home. Mild allergic reactions were managed by stopping the infusion and giving injection chlorpheniramine $10 \mathrm{mg}$ i.v. slowly. All emergency drugs (like adrenaline, hydrocortisone etc.) were readily available to manage any adverse reactions. Heamoglobin was analysed by sysmex and Serum ferritin was analysed by VIDAS FERRITIN.

The primary efficacy endpoint was the percentage of subjects achieving $\mathrm{Hb}$ greater than $12 \mathrm{gm} / \mathrm{dl}$ between baseline and end of study. Major secondary endpoints, in ranked order of testing, were: maximum increase in $\mathrm{Hb}$ and serum ferritin over 3 weeks; Number of doses of the study medication needed; adverse drug reactions and compliance to study medications.

To detect the increase in $\mathrm{Hb} \%$ with $90 \%$ power at the $5 \%$ significance level, we calculated that 50 women needed to be recruited to each group. All analyses were conducted using SPSS for Windows, version 10.0 (SPSS Inc., Chicago, IL, USA). The effect of iron supplementation on maternal iron status was analysed by Student's t-test.

\section{RESULTS}

In Table 3 it was noted that the 50 women who were treated with the study medication were similar in their demographic profile. All the women were haemodynamically stable at the time of inclusion into the study. The median age group was 24 years. We did not have many subjects in extremes of age group. Most women belonged to low socio economic status, class four upper lower group according to Kuppuswamy 2012 classification. In our study we had more number of booked cases when compared unbooked cases in both the study groups.

Table 3: Demographic data of the treatment group.

\begin{tabular}{|ll|}
\hline Demographic table & Ferric carboxymaltose \\
\hline Age (years) & $24.24 \pm 3.80$ \\
\hline Socioeconomic status & \\
\hline Upper (I) & $1(2 \%)$ \\
\hline Upper middle (II) & $5(10 \%)$ \\
\hline Lower middle (III) & $6(12 \%)$ \\
\hline Upper lower (IV) & $28(56 \%)$ \\
\hline Lower (V) & $10(20 \%)$ \\
\hline Booking & $38(76 \%)$ \\
\hline Booked & $12(24 \%)$ \\
\hline Unbooked & \\
\hline Parity & $36(72 \%)$ \\
\hline Primi & $14(28 \%)$ \\
\hline Multi &
\end{tabular}


Table 4: Risk factor for postpartum anemia.

\begin{tabular}{|ll|}
\hline Risk factor & Ferric carboxymaltose \\
\hline PPH & $10(20 \%)$ \\
\hline APH & $2(4 \%)$ \\
\hline Hypertension disorders & \\
\hline Gestational hypertension & $1(2 \%)$ \\
\hline Mild preeclampsia & $3(6 \%)$ \\
\hline Severe preeclampsia & $1(2 \%)$ \\
\hline Exclusive breast feeding & $49(98 \%)$ \\
\hline Antenatal anemia & $29(58 \%)$ \\
\hline Yes & $21(42 \%)$ \\
\hline No & $45(90 \%)$ \\
\hline H/o of intake of oral iron & $5(10 \%)$ \\
\hline Yes & $1(2 \%)$ \\
\hline $\begin{array}{l}\text { No } \\
\text { H/o bleeding PR, malena, } \\
\text { hematemesis }\end{array}$ & $1(2 \%)$ \\
\hline $\begin{array}{l}\text { H/o heavy menstrual } \\
\text { bleeding }\end{array}$ & \\
\hline
\end{tabular}

PPH- Postpartum hemorrhage; APH- Ante partum

hemorrhage; H/o- history of.

The most common risk factor for postpartum anemia in the study population was antenatal anemia (58\%). The other risk factors were few and insignificant (Table 4).

Table 5: Mode of delivery.

\begin{tabular}{|ll|}
\hline Type of delivery & Ferric carboxymaltose \\
\hline LSCS & $22(44 \%)$ \\
\hline Vaginal delivery & $28(56 \%)$ \\
\hline
\end{tabular}

The most common mode of delivery was vaginal (56\%) of which four cases had instrumental delivery. However the difference between vaginal and caesarean was not statistically significant (Table 5).

Table 6: Comparison of mean haemoglobin before and after treatment.

\begin{tabular}{|ll|}
\hline \multicolumn{2}{|l|}{ Ferric carboxymaltose } \\
\hline Baseline Hb & \\
\hline 0 day & $8.095 \pm 0.505$ \\
\hline 21 day & $12.761 \pm 0.968$ \\
\hline P value & $0.000 * *$ \\
\hline Absolute raise & $4.666 \pm 0.463$ \\
\hline Percentage raise & $57.64 \%$ \\
\hline Minimum raise & 2.7 \\
\hline Maximum raise & 6.4 \\
\hline
\end{tabular}

Tables 6, 7 and Figure 2 show the comparison of mean haemoglobin and serum ferritin levels on day 0 and day 21 of therapy. The mean baseline haemoglobin was $8.095 \pm 0.505$. After three weeks of treatment with ferric carboxymaltose, rise in haemoglobin was $12.761 \pm 0.968$. The haemoglobin increased by $4 \mathrm{gm} \%$ in three weeks. The mean baseline serum ferritin was $15.5 \pm 20.5$. After three weeks of treatment with ferric carboxymaltose, rise in serum ferritin was $110.3 \pm 44$. The rise in serum ferritin and haemoglobin following treatment was statistically significant.

Table 7: Comparison of serum ferritin before and after treatment.

\begin{tabular}{|ll|}
\hline Baseline & Serum ferritin \\
\hline 0 day & $15.5 \pm 20.5$ \\
\hline 21 day & $110.3 \pm 44.5$ \\
\hline P value & $0.000^{* *}$ \\
\hline Absolute raise & $94.8 \pm 24$ \\
\hline Percentage raise & $611.61 \%$ \\
\hline Minimum raise & 23.63 \\
\hline Maximum raise & 191.5 \\
\hline
\end{tabular}

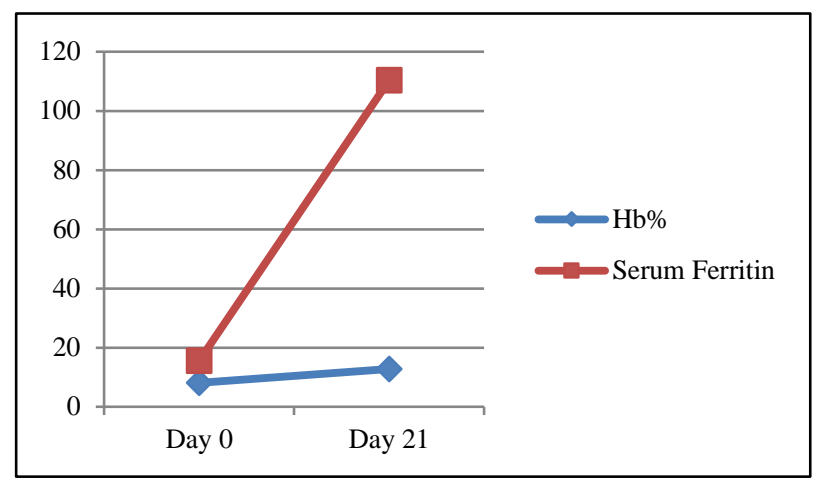

Figure 2: Comparison of $\mathrm{Hb} \%$ and serum ferritin before and after treatment.

The side effects noted were very few and insignificant. $96 \%$ of women did not have any adverse effects. There were no haemodynamic disturbances observed either during infusion or after infusion (Table 8).

Table 8: Adverse drug reactions.

\begin{tabular}{|ll|}
\hline & Ferric carboxymaltose \\
\hline No reactions & $48(96 \%)$ \\
\hline Breathlessness & $1(2 \%)$ \\
\hline Myalgia & $1(2 \%)$ \\
\hline Urticaria & $2(4 \%)$ \\
\hline Burning at Injection Site & 0 \\
\hline Epigastric pain & 0 \\
\hline Headache & $1(2 \%)$ \\
\hline
\end{tabular}

Most of the women (92\%) of women required two doses of ferric carboxymaltose (Table 9).

Table 9: Number of doses taken in ferric carboxymaltose.

\begin{tabular}{|ll|}
\hline Number of doses & Ferric carboxymaltose \\
\hline $\mathbf{1}$ & $4(8 \%)$ \\
\hline $\mathbf{2}$ & $46(92 \%)$ \\
\hline
\end{tabular}


Out of the 50 women recruited for the study, we lost to follow up in four patients $(8 \%)$ and two women dropped out of the study due to reactions (Figure 1). Compliance to the study medication was $88 \%$.

\section{DISCUSSION}

Anaemia is one of the leading causes of disability and is a major global public health problem. ${ }^{23}$ Even though the problem of iron deficiency in pregnancy is adequately emphasized, very little attention has been paid to postpartum anemia. The treatment of postpartum iron deficiency anemia with any form of iron therapy aims at raising serum $\mathrm{Hb}$ levels by $2.4-4.6 \mathrm{~g} / \mathrm{dl} .{ }^{13,24-27}$ In a study conducted by Seid et al they found that ferric carboxymaltose was superior to oral iron in improving iron stores, as measured by ferritin, and in increasing TSAT, an indicator of iron available for erythropoiesis. They found that one course of ferric carboxymaltose resulted in significantly replenished iron stores at study completion (day 42), whereas six weeks of oral iron did not. ${ }^{24}$ In another study by Urvashi et al, they found that in the FCM group there was maximum increase in $\mathrm{Hb} \%$ from the baseline $\mathrm{Hb}$ i.e. mean rise in $\mathrm{Hb}$ of $3.1 \mathrm{gm} / \mathrm{dl}$ after four weeks. ${ }^{28}$ In our study we found that one course of ferric carboxymaltose increased the $\mathrm{Hb}$ increased by $4 \mathrm{gm} \%$ in three weeks.

In our study, serum ferritin was used as an indicator of iron storage. Although ferritin levels are low in pregnancy due to plasma dilution, ferritin remains a reliable indicator of iron deficiency, where a cutoff level of $<15 \mu \mathrm{g} / \mathrm{l}$ is used. ${ }^{29,30}$ We found that serum ferritin increased by $94.8 \pm 24$ after ferric carbxymaltose. Seid et al reported that the ferritin levels were replenished at 42 day in the patients receiving FCM, but not in the oral iron group $(238 \mathrm{ng} / \mathrm{ml}$ versus $21 \mathrm{ng} / \mathrm{ml} ; \mathrm{p}<0.0001) .{ }^{24}$ Breymann et al reported mean ferritin levels increased from $39.9 \mu \mathrm{g} / \mathrm{l}$ at baseline to $568.2 \mu \mathrm{g} / \mathrm{l}$ at week one and $161.2 \mu \mathrm{g} / \mathrm{l}$ at week 12. The changes from baseline were significantly higher in the iron carboxymaltose group compared with the control group for all visits, including week $12(\mathrm{p}<0.0001) .{ }^{29}$ In another study by Rathod et al, they observed that in FCM group, mean ferritin level increase from $35 \mathrm{ng} / \mathrm{dl}$ to $356 \mathrm{ng} / \mathrm{dl}$ at two weeks and $142 \mathrm{ng} / \mathrm{dl}$ at six weeks. ${ }^{31}$

The reported incidence of adverse effects with FCM therapy was between $6.3 \%$ and $10.6 \% .^{24,25,27}$ In the study by Rathod et al, they had one patient who reported arthralgia and tingling sensation of feet $15 \mathrm{~min}$ after completing administration of the full dose of FCM. ${ }^{31}$ In our study only $4 \%$ of women had adverse effects, all of which reduced following completion of the infusion.

\section{CONCLUSION}

It is preferable to prevent postpartum anemia by treating antenatal anemia and practising active management of third stage of labour to prevent excessive blood loss during delivery. Ferric carboxymaltose is safe and effective and permits a rapid and reliable correction of postpartum anemia. The ability to administer $1000 \mathrm{mg}$ doses in a single sitting, makes it convenient, improving the compliance making it suitable for outpatient use.

It has fewer adverse reactions and there is no evidence of risk to the infant while breastfeeding, or effect on lactation making it the first-line drug in the management of postpartum iron deficiency anemia. Pharmacoeconomic studies are needed to compare cost utilization differences between ferric carboxymaltose and other available iron preparations. Larger randomised multicentric studies are required to decide the ideal preparation of parental iron.

\section{Funding: No funding sources \\ Conflict of interest: None declared \\ Ethical approval: The study was approved by the Institutional Ethics Committee}

\section{REFERENCES}

1. Bodnar LM, Scanlon KS, Freedman DS, Siega-Riz AM, Cogswell ME. High prevalence of postpartum anemia among low-income women in the United States. Am J Obstet Gynecol. 2001;185:438-43.

2. Bodnar LM, Cogswell ME, McDonald T. Have we forgotten the significance of postpartum iron deficiency? Am J Obstet Gynecol. 2005;193:36-44.

3. Kouser S, Kouser S, Malik M, Malik A. Safety and efficacy of intravenous iron therapy in postnatal patients with iron deficiency anemia. J South Asian Fed Obstet Gynaecol. 2011;3:25-7.

4. Somdatta P, Reddaiah VP, Singh B. Prevalence of anaemia in the postpartum period: A study of a North Indian village. Trop Doct. 2009;39:211-5.

5. Ahmed K, Saqid I, Yousuf AW. Injectable iron therapy: intramuscular vs. intravenous therapy. Biomedics. 2000; 16:44-7.

6. Pernoll ML. Iron deficiency anemia. In: Pernoll ML, ed. Benson and Pernoll's handbook of obstetrics and gynecology. 10th edn. Columbus $(\mathrm{OH})$ : The McGraw-Hill Companies, Inc.; 2001:435-437.

7. Sherrets D, Cusick S, Grosse S, Amendah D. Iron deficiency anemia among pregnant women: Screening and preventive medication. 2009. Available from: http://www.businessgrouphealth.org/preventive/topic s/ida_pregnancy.cfm. Accessed on 10 May 2011.

8. Sutherland T, Bishai DM. Cost-effectiveness of misoprostol and prenatal iron supplementation as maternal mortality interventions in home births in rural India. Int J Gynaecol Obstet. 2009;104:189-93.

9. Milman N. Postpartum anemia I: Definition, prevalence, causes, and consequences. Ann Hematol. 2011;90:1247-53.

10. James A, Patel S, Dinh Q. Impact of anemia on medical resource utilization and hospital cost in women with obstetrical bleeding. Blood. 2007;110:5168.

11. Beard JL, Hendricks MK, Perez EM, Murray-Kolb LE, Berg A, Vernon-Feagans L, et al. Maternal iron 
deficiency anemia affects postpartum emotions and cognition. J Nutr. 2005;135:267-72.

12. Perez EM, Hendricks MK, Beard JL, Murray-Kolb LE, Berg A, Tomlinson M, et al. Mother-infant interactions and infant development are altered by maternal iron deficiency anemia. J Nutr. 2005; 135:850-5.

13. Bodnar LM, Siega-Riz AM, Miller WC, Cogswell ME, McDonald T. Who should be screened for postpartum anemia? An evaluation of current recommendations. Am J Epidemiol. 2002;156:90312.

14. CDC criteria for anemia in children and childbearingaged women. MMWR Morb Mortal Wkly Rep. 1989;38:400-4.

15. Zimmermann MB. Methods to assess iron and iodine status. Br J Nutr. 2008;99(3):S2-9.

16. Silverman JA, Barrett J, Callum JL. The appropriateness of red blood cell transfusions in the peripartum patient. Obstet Gynecol. 2004;104:10004.

17. Hallberg L, Ryttinger L, Solvell L. Side effects of oral iron therapy. A double-blind study of different iron compounds in tablet form. Acta Med Scand Suppl. 1966;459:3-10.

18. Solvell L. Oral iron therapy-side effects. In: Hallberg L, Harwerth HG, Vannotti A, eds. Iron Deficiency: Pathogenesis, Clinical Aspects, Therapy. 1st edn. London: Academic Press; 1970:573-583.

19. National Institute for Health and Clinical Excellence: Clinical guideline 39: Anaemia management in people with chronic kidney disease (CKD). 2006. Available from: http://guidance.nice.org.uk/CG39. Accessed on 3 February 2011.

20. Brookhart MA, Schneeweiss S, Avorn J, Bradbury BD, Liu J, Winkelmayer WC. Comparative mortality risk of anemia management practices in incident hemodialysis patients. JAMA. 2010;303:857-64.

21. Folb PI. The safety of iron dextran and a comparison with iron sucrose for intravenous use: a short report to the world health organization advisory committee on the safety of medicines. Available from: http://www.who.int/medicines/areas/quality_safety/s afety_efficacy/Addendum.pdf. Accessed on 3 February 2011.

22. Lyseng-Williamson KA, Keating GM. Ferric carboxymaltose: a review of its use in iron-deficiency anaemia. Drugs. 2009;69:739-56.
23. World Health Organization. Anemia prevention and control. Geneva, Switzerland: World Health Organization; 2011. Available from: http://www.who.int/medical_devices/initiatives/anae mia_control/en. Accessed on 10 February 2014.

24. Seid MH, Derman RJ, Baker JB, Banach W, Goldberg $\mathrm{C}$, Rogers R. Ferric carboxymaltose injection in the treatment of postpartum iron deficiency anemia: A randomized controlled clinical trial. Am J Obstet Gynecol. 2008;199:435.e1-7.

25. Breymann C, Gliga F, Bejenariu C, Strizhova N. Comparative efficacy and safety of intravenous ferric carboxymaltose in the treatment of postpartum iron deficiency anemia. Int $\mathbf{J}$ Gynaecol Obstet. 2008;101:67-73.

26. Giannoulis C, Daniilidis A, Tantanasis T, Dinas K, Tzafettas J. Intravenous administration of iron sucrose for treating anemia in postpartum women. Hippokratia. 2009;13:38-40.

27. Van Wyck DB, Martens MG, Seid MH, Baker JB, Mangione A. Intravenous ferric carboxymaltose compared with oral iron in the treatment of postpartum anemia: A randomized controlled trial. Obstet Gynecol. 2007;110:267-78.

28. Singh U, Singh N. Anemia in peuperium: Comparative study of effcacy and safety of oral iron, iron sucrose and ferric carboxymaltose. Indian J Appl Res. 2015;6:741-2.

29. Mei Z, Cogswell ME, Parvanta I, Lynch S, Beard JL, Stoltzfus RJ, et al. Haemoglobin and ferritin are currently the most efficient indicators of population response to iron interventions: an analysis of nine randomised controlled trials. J Nutr. 2005;135:197480.

30. Van den Broek NR, Letsky EA, White SA, Shenkin A. Iron status in pregnant women: which measurements are valid? $\mathrm{Br} \mathrm{J}$ Haematol. 1998;103:817-24.

31. Rathod S, Samal SK, Mahapatra PC, Samal S. Ferric carboxymaltose: a revolution in the treatment of postpartum anemia in Indian women. Int J Appl Basic Med Res. 2015;5(1):25-30.

Cite this article as: Krishna K, Krishna K, Teja GND. Role of ferric carboxymaltose in the treatment of postpartum anemia in a tertiary care hospital in Andhra Pradesh. Int J Reprod Contracept Obstet Gynecol 2021;10:3889-94. 